\title{
Utopia/Dystopia - Identity and Connectivity in Social Media
}

\author{
Silke Roesler-Keilholz \\ University of Regensburg, Regensburg, Germany
}

\begin{abstract}
New technologies, and so is the Internet, have to be discussed and located between utopia and dystopia. Especially when dealing with questions of identity. While discretion and privacy were important concepts of the self in a non-virtual world in the past, Joshua Meyrowitz name the "Internet-privacy-paradox" as a feature of life in the age of Web 2.0. Monica T. Whitty and Adam N. Joinson, on the other hand, define the "truth-lies-paradox" as dominant for virtual life. Meyrowitz marks the frivolous publication of private data as the main problem of Internet use. Known as the "strangers-on-the-train-phenomenon", also online users would tell details about their life in a completely open and surveilled environment—obviously not being aware of the danger this behavior is accompanied by. Whitty and Joinson state that the online environment would trigger its users' openness and deception in general. They also stress the fact, that the World Wide Web would cause ambivalences in self-presentation: For many online users, the self-presentation opportunities provided by the Internet would mean they were faced with a dilemma-visual anonymity may make candid self-disclosure easier, but it also enables people to put a "gloss" on the information they provide. The author puts a closer look at the ambivalence of Internet use by reflecting the terms paradox, connectivity and constructedness.
\end{abstract}

Keywords: identity, privacy, paradox, construction

When it comes to questions of identity and social media one can't talk about it without perceiving "paradoxes": life on the screen must be situated between truth and lies, self-presentation and concealment, reception and production. While in the past life on the screen was described in a (completely) positive way it now meets criticism. Acting and "living" in and on the web might be tempting, convenient and freeing but also dangerous if one acts unreflected.

The author's thoughts follow this structure:

(1) First of all the study introduces some basic statements about identity and self-presentation relating to personal home pages (for example: Facebook, Xing, LinkedIn) which many of you are familiar with. The term of "constructedness" will be central in this first part.

(2) In a second step the study focusses on virtual identities in general and on the concepts of theoretical implications they are accompanied by. Sherry Turkle's and A. R. Stone's term of multiplicity will be relevant for this thread.

(3) Afterwards the author looks on identity crisis or negative aspects of Internet use — or maybe one should say abuse.

(4) In a final step the paper introduces two theoretical paradoxes which seem to explain different occurrences of identity in the age of Web 2.0. The author wants to ask, if the "paradox" per se might work as

Silke Roesler-Keilholz, Dr. phil., Media Studies Department, University of Regensburg. 
the central concept and figure of the web and digital life in general.

The theoretical argumentation will be supplemented and stressed by stills of the stunning Johan Renck movie Downloading Nancy from 2008. Sundance Film Festival Director Geoff Gilmore introduced Downloading Nancy as "the most intense film of the festival" (Davis, 2008). We watch Nancy (Maria Bello), a wounded woman who is days away from finally cracking.

Let me quote Erik Davis (2008) in the following: Nancy's marriage to the stone cold golf-obsessed Albert (Rufus Sewell) lacks emotion and intimacy, and so Nancy turns to the online world for a way out of her marriage, out of herself and out of her life. She is not looking to have an affair; a fling with an online buddy - something to clear her mind, provide some excitement to an otherwise empty life. Instead, she is looking to hire someone to kill her. Not just to kill her; to torture her physically, emotionally, sexually - then to strike when she least expects it. In the first picture we watch Nancy being online, in the second example she is tortured by her hired murderer, while in the third stills that one is visiting Nancy's husband. The last picture presents the lonesome widower reading a last note by his wife.

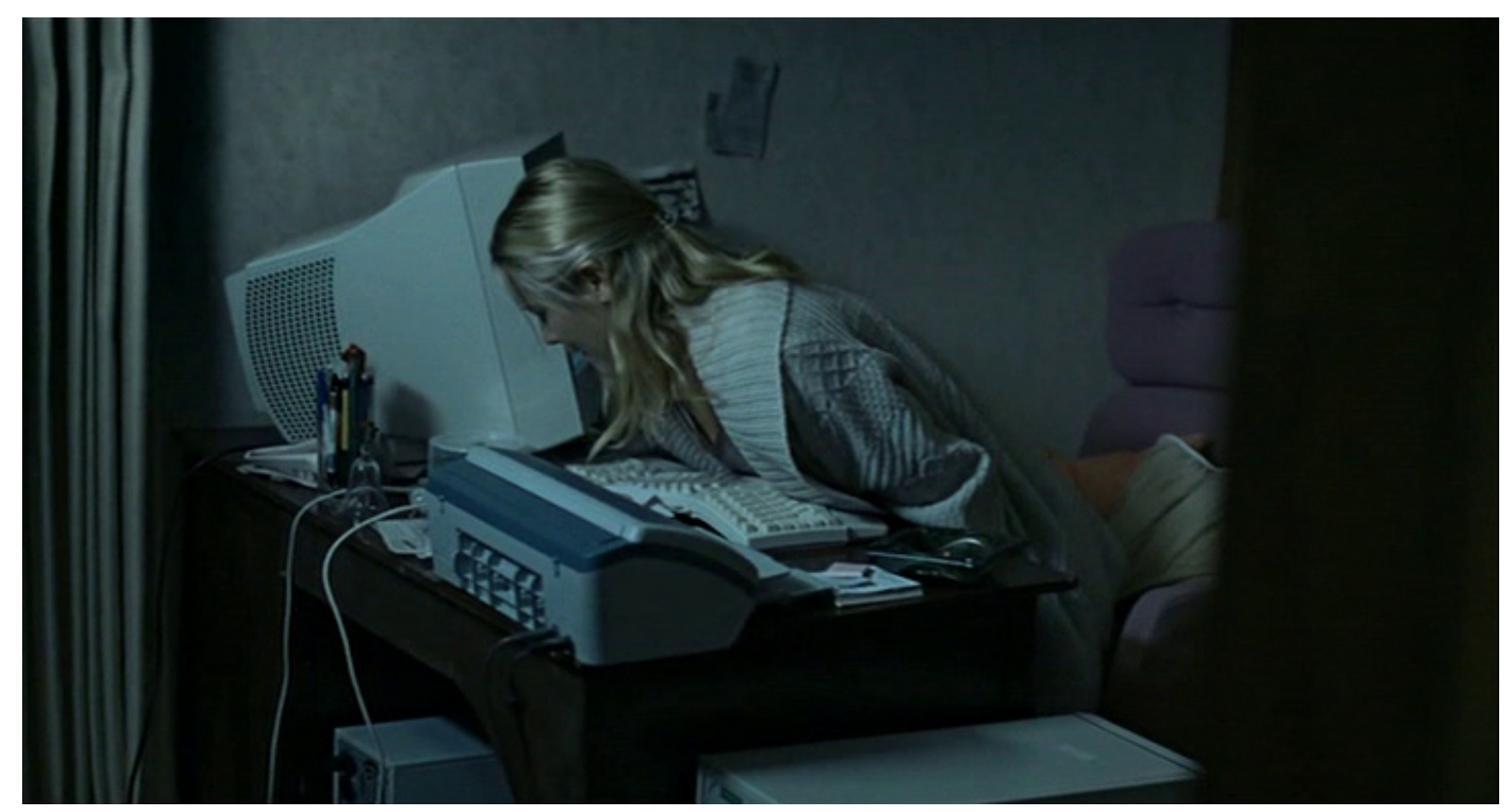

Figure 1. Downloading Nancy (Johan Renck, USA 2008).

\section{Identity \& Self-Presentation}

While the traditional notion of identity assumes the homogeneity and stability of personal identity, postmodern identity is understood as a patchwork or pastiche of independent and contradictory sub-identities, which are to be constructed anew in everyday identity work and related to one another to support a sense of coherence (Mestvirishvili, 2012). Analogously, the self is also no longer understood as a homogeneous and static entity, but as a dynamic and multiple structure, which is composed of various self-aspects. The multiple self has also been theoretically modelled as a dialogical self, in which the individual self-aspects constitute the voices of an inner dialog. While the combined self-aspects comprise the entire content related to one's person and the processes acting upon them, with sub-identities only the especially relevant self-aspects are implied (Döring, 1999, p. 255). To Nicola Döring "identity" is accordingly the more narrow, "self" the broader concept. 


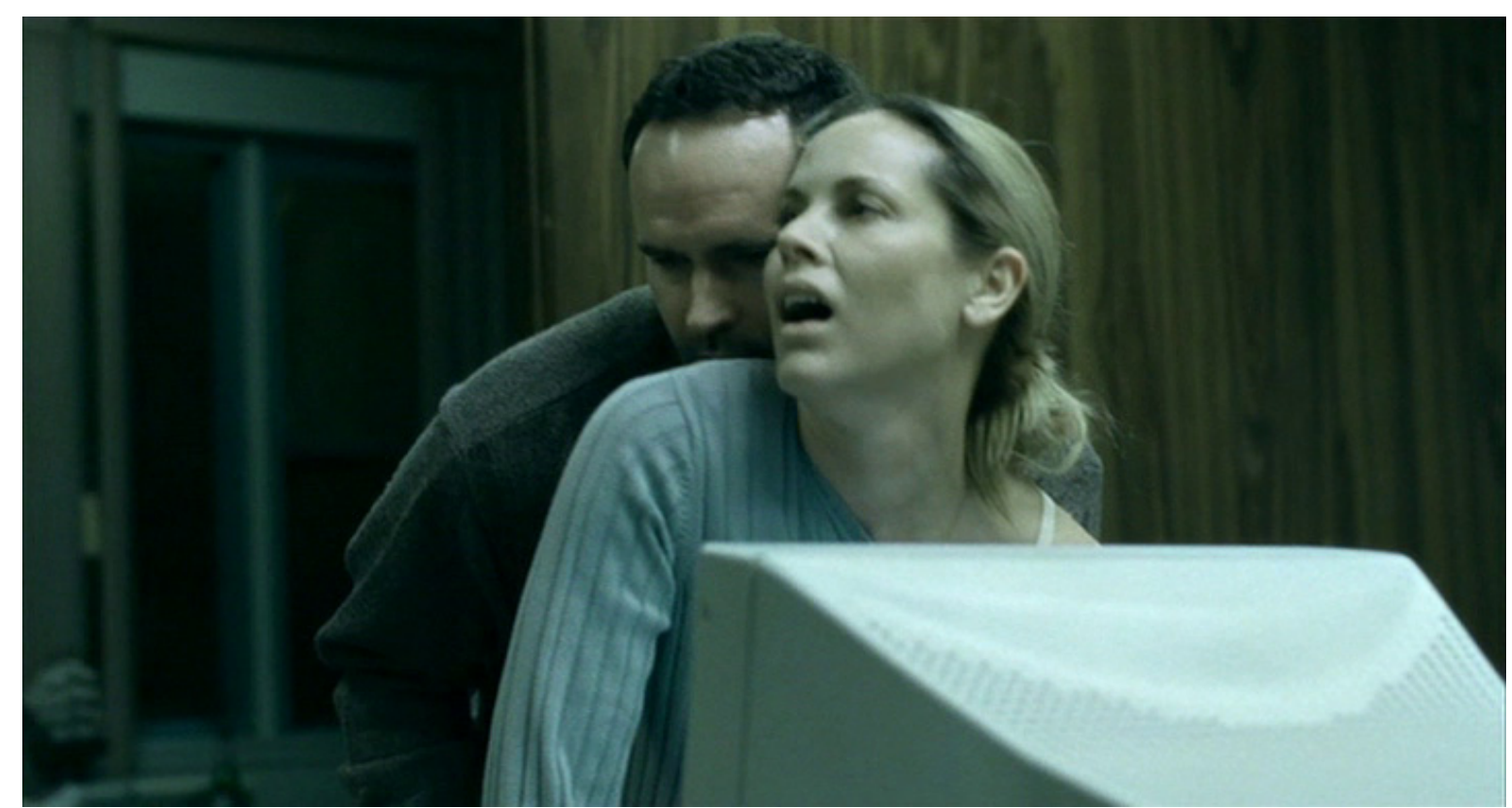

Figure 2. Downloading Nancy (Johan Renck, USA 2008).

Common to concepts such as "patchwork identity", "narrative identity", "multiple self", "dynamic self", and "dialogical self" is a focus on constructedness, change and diversity. Precisely these aspects are to be found on personal home pages: The home page is always "under construction": it can be regularly updated to reflect the latest self-conceptions. Also it easily joins diverse diachronic self-aspects and sub-identities with the internal and external links in its hypertext-structure. According to Döring no other medium seems more exactly suited than the personal home page to fulfilling the present-day demands of identity work on the charged field of differentiation on the one hand and construction of coherence and meaning on the other hand. In her opinion personal home page construction promotes the systematic answering of the identity-critical "Who am I?"-question and supports the internalization of the individual answers. Representing one's patchwork identity on one personal home page can foster the feeling of self-integration and self-effectiveness.

In face-to-face-situations people are often restricted or handicapped in their self-presentational behavior, e.g., because they are stereotyped or stigmatized at first glance, because they don't reach relevant audiences, or cannot effectively control their spontaneous verbal or nonverbal reactions.

Like Döring (1999) explains impression management or self-presentation are often regarded as inauthentic and manipulative practices. But psychological research has revealed that whenever other people are able to observe our behavior directly or to receive information about it, we are careful about what type of impression we leave behind and we actively shape our self-presentation. The general aim of self-presentation as an everyday phenomenon is not to deceive or harm other people but to interact and communicate with them adequately and usefully. Self-presentation research, which has been decisively influenced by the sociologist Erving Goffman (1959) and his metaphor of dramatic performance in everyday life, emphasizes the prosocial aspects of impression management in terms of fostering friendliness and closeness and avoiding conflicts, embarrassment, shame and anger. In face-to-face-situations people are often restricted or handicapped in their self-presentational behavior, e.g., because they are stereotyped or stigmatized at first 
glance, because they don't reach relevant audiences, or cannot effectively control their spontaneous verbal or nonverbal reactions.

According to Döring (1999) the personal home page, addresses these problems and is especially well suited for an elaborate strategical self-presentation. One can express oneself extensively and without disturbance, falling back on various modalities and codes. Being represented on the web with an attractive, information-rich, professional or humorous personal home page may enhance the impression we make on people who are not yet familiar with us personally. The personal home page can also supplement the face-to-face impressions we make on people who actually are familiar with us personally. There can also be public relations work intended for a certain collective identity or marginalized social group to which one belongs (handicapped people, homosexual people, ethnic minority groups) and whose public image one would like to influence.

Let me emphasize: As a medium of nearly unrestricted self-presentation, the personal home page obviously supplements our means of impression management through interpersonal and public relations communication. Internet identity is an actively constructed presentation of oneself. Especially the social web is a place to express and expose identity in a social environment and in so far online activities may affect the offline identity.

\section{Virtual Identities}

The US-American MIT professor Sherry Turkle sees both computers and information networks as basically identity-transforming, as they erode boundaries of real and virtual, human and machine, and enable constant self-invention. This is especially the case with virtual communities like MUDs (Multi User Dungeons; like the online game World of Warcraft), which according to Turkle "make possible the creation of an identity so fluid and multiple that it strains the limits of the notion. Identity, after all, refers to the sameness between two qualities, in this case between a person and his or her persona. But in MUDs, one can be many" (Turkle, 1995, p. 12). In a similar rhetorical move, Stone (1995, p. 42) states: "[T]he technosocial, the social mode of the computer nets, evokes unruly multiplicity as an integral part of social identity". Both Turkle and Stone frame the Internet and virtual communities as alternative social configurations where the rules of "making the self" are subverted. Spaces of media use become understood as mere terminals from which one sets out to "travel in cyberspace", leaving behind the confines of embodiment, along with the markers of identity and difference.

For Turkle computers and especially the Internet are "changing the way we think, the nature of our sexuality, the forms of our communities, our very identities". In this process, the self becomes understood as multiple and fluid, and is able to perform several characters. Turkle thus reads computers as illustrations of poststructural theories on dispersed identities and also as means of bringing these theories "down to earth". According to Turkle the play with multiple identities_-inventing, taking up, living, and discarding different personae online - can be seen as illustrations of voluntarism, belief in the possibilities of international identity-formation.

Stone (1996, pp. 2-3) sees the Internet as a site for floating identities that are independent from what she calls a "root identity", the conventional assumption of the self as coherent. According to Stone, the net is a space in with [Folie 5] "the transgender is the natural body. The nets are spaces of transformation, identity factories in which bodies are meaning machines, and transgender-identity as performance, as play, as wrench 
in the smooth gears of the social apparatus of vision —is the ground state" (pp. 180-181). This is to say that different crossings from one gender and identity position to another are so common online that gender identity, identifiable as either female or male, is no longer a viable category. Identities are about play and masks, and authenticating them through references to one's embodied locations translates as both an anachronistic longing for a coherent self and a misconception of what identities are about.

According to Turkle (1995, p. 14.) as "people can play at having different genders and different lives, it isn't surprising that for some this play has become as real as what we conventionally think of as their lives, although for them this is no longer a valid distinction". If gender is thought of as something one has, rather than something one is constituted by, this may be a logical outcome.

Although Turkle and Stone discuss the self as split—and not as connectivity—, this self can intentionally "do" identities, create parallel lives, play around with genders and sexualities, and choose which ones to embrace and prioritize. Especially in Turkle's Life on the screen, there is surprisingly little emphasis on the social conditions of subjectivation, on the self as a product of various social technologies. That is, the particular social location of the performers is not seen as formative of the possible selves performed. In fact, parallel virtual lives are presented as "ways out" from an unsatisfied life.

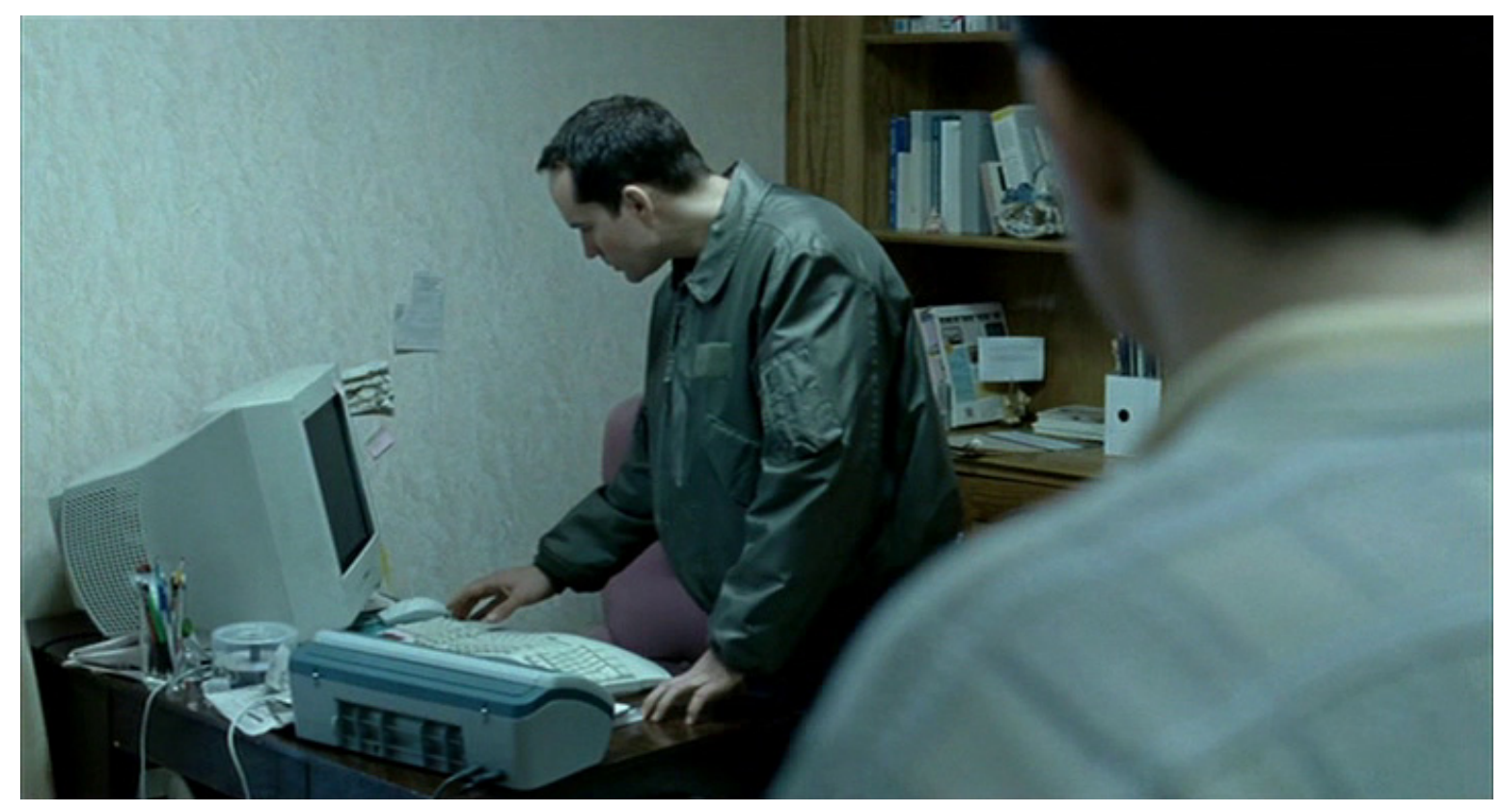

Figure 3. Downloading Nancy (Johan Renck, USA 2008).

\section{Identity Crisis}

In a little more than a decade, the Internet has revolutionized mediated communication and communication flow. With the pace of change and the emergence of Web 2.0 over this time, researchers have continued to struggle with explaining various positive and negative effects of Internet use that have garnered attention. Some have suggested that Internet use can enhance living conditions by providing access to diverse information, widen users' social circles, and enhance psychological well-being. Others have considered some negative effects of the Internet, arguing that it can be an isolating medium leading to loneliness, less social interaction with family members and friends and clinical depression. 


\section{Internet Addiction}

One negative effect that has received considerable attention over the last several years is the extent to which people may become addicted to the Internet. The ongoing evolution of Internet use and growth in the amount of time people spend using the Internet has fueled this concern. Researchers have used different terms to describe very similar types of behavior. These include problematic Internet use, pathological Internet use, Internet dependency and Internet addiction. The loss of control, chattering hands, flickering eyes and withdrawal syndromes characterize this form of addiction. By addicts the Internet is used as an escape of the "real world" which often causes social isolation.

\section{Cyber-bullying}

Another negative aspect of Internet use is cyber-bullying. Cyber-bullying has been defined as when the Internet, cell phones or other devices are used to send or post text or images intended to hurt or embarrass another person. Cyber-bullying can be as simple as continuing to send an e-mail to someone who has said they want no further contact with the sender, but it may also include threats, sexual remarks, pejorative labels, ganging up on victims by making them the subject of ridicule in forums, and posting false statements as fact aimed at humiliation.

Cyber-bullies may disclose victims' personal data at websites or forums or may pose as the identity of a victim for the purpose of publishing material in their name that defames or ridicules them. Some cyber-bullies may also send threatening and harassing emails and instant messages to the victims, while other post rumors or gossip and instigate others to dislike and gang up on the target. The bullying occurs via email, text messaging, posts to blogs, and Web sites.

\section{Pro-anorexia Websites}

Internet use is also associated with potential risk when it provides adolescents and young adults with access to information on a broad variety of medical issues, including eating disorders such as anorexia nervorsa (AN). In fact searching for "anorexia" on any common search engine produces a plethora of information, including links to "pro-anorexia" (henceforth "pro-ana") websites. These websites have recently emerged as an online movement supporting the virtues of AN. Many offer information, support, and a sense of community to individuals with an eating disorder. Unfortunately, many of these websites contain controversial and dangerous content. Some promote AN as a lifestyle choice, speaking about "thinspiration". These sections provide the most obvious visual representations of the distorted body image typified in AN. Pictures of skinny young females aimed to provide encouragement and serve as motivation for continued and sustained weight loss. Healthcare providers, parents, and caregivers must have fundamental knowledge and understandings of these websites, as well as their potential risk.

\section{Conclusion of Paradoxes}

So what do all of these facets of Internet use we heard about have in common? While discretion and privacy were important concepts of the self in the past, Joshua Meyrowitz name the "internet-privacy-paradox" as a feature of life in the age of Web 2.0. Monica T. Whitty and Adam N. Joinson, on the other hand, define the "truth-lies-paradox" as dominant for virtual life.

Meyrowitz marks the frivolous publication of private data as the main problem of Internet use. Known as the "strangers-on-the-train-phenomenon", also online users would tell details about their life in a 
completely open and surveilled environment—obviously not being aware of the danger this behavior is accompanied by.

Whitty and Joinson state that the online environment would trigger its users' openness and deception in general. They also stress the fact, that the World Wide Web would cause ambivalences in self-presentation: For many online users, the self-presentation opportunities provided by the Internet would mean they were faced with a dilemma - visual anonymity may make candid self-disclosure easier, but it also enables people to put a "gloss" on the information they provide. Especially for teenagers it would be extremely difficult to situate ones personality between the online self and the "real me" and to handle the balancing act between honesty and dishonesty.

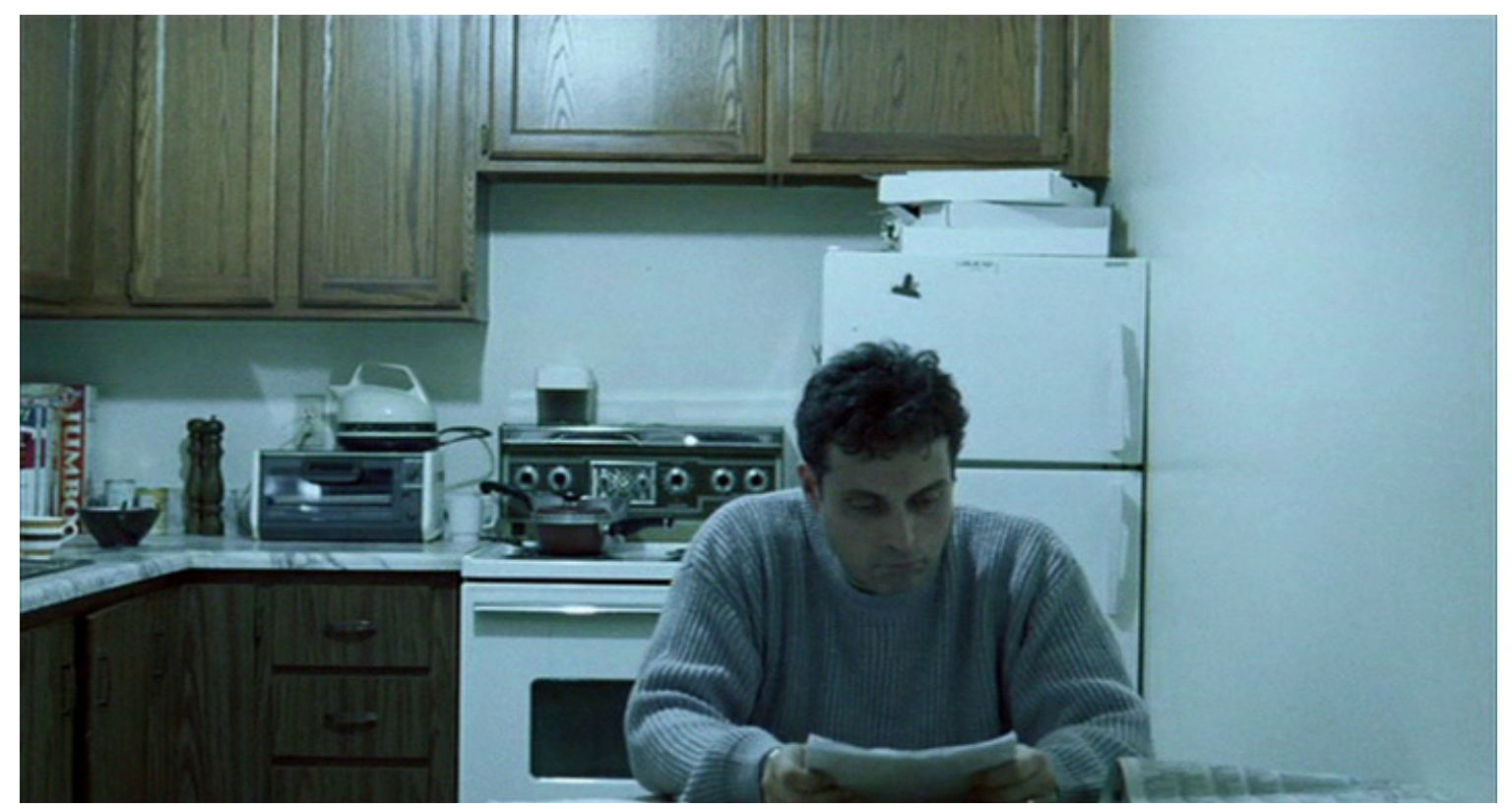

Figure 4. Downloading Nancy (Johan Renck, USA 2008).

After all the author wants to stress the fact that new technologies, and so is the Internet have to be discussed and located between utopia and dystopia. Especially when dealing with questions of identity. On the one hand there are benefits: the freedom (of online activities) results in new opportunities for society as a whole, especially the ability for people to explore the roles of gender and sexuality in a manner that can be harmless, yet interesting and helpful to those undertaking the change. Online identity has given people the opportunity to feel comfortable in wide-ranging roles, some of which may be underlying aspects of the user's life that the user is unable to portray in the real world. On the other hand there are concerns where most of them deal with child pornography and sexual abuse. The paper wanted to state that one has to beware of the technological potential of the web and one has to take care of one's privacy. The "paradox" might work as a term and tool for analyzing processes in the world wide web.

\section{References}

Davis, E. (2008). Sundance review: Downloading Nancy. Retrieved August 28, 2016, from http://www.moviefone.com/2008/01/21/sundance-review-downloading-nancy/

Döring, N. (1999). Sozialpsychologie des Internet (Social psychology of the Internet).Göttingen: Hogrefe. Goffman, E. (1959). The presentation of self in everyday life. London: Doubleday. 
Mestvirishvili, M. (2012). National identity: Models, elements and characteristics. Retrieved from http://iseees.berkeley.edu/sites/default/files/u4/Mestvirishvili_fr.pdf

Meyrowitz, J. (2002). Post-Privacy America. In R. Weiß, \& J. Groebel (Eds.), Privatheit im Öffentlichen Raum: Medienhandeln zwischen Individualisierung und Entgrenzung (Privacy in public space: Medial action between individualisation and separation) (pp. 153-204). Opladen: Leske + Budrich.

Stone, A. R. (1995). The war of desire and technology at the close of the Mechanical Age. Cambridge: MIT Press.

Turkle, S. (1995). Life on the Screen: Identity in the age of Internet. London: Phoenix.

Whitty, M. T., \& Joinson, A. N. (2009). Truth, Lies, and Trust on the Internet. London: Routledge. 